\title{
An ELISA-on-a-Chip Biosensor System for Early Screening of Listeria monocytogenes in Contaminated Food Products
}

\author{
Sung-Min Seo, ${ }^{\dagger+a}$ II-Hoon Cho, ${ }^{\dagger+\lambda}$ Joo-Ho Kim, ${ }^{+\infty}$ Jin-Woo Jeon, Eun-Gyoung Oh, \\ Hong-Sik Yu, Soon-Bum Shin, ${ }^{\$}$ Hee-Jung Lee, and Se-Hwan Paek ${ }^{,+\cdots, *_{1}^{*}}$ \\ ${ }^{\dagger}$ Program for Bio-Aficroststem Technology and ${ }^{\ddagger}$ Graduate School of Life Sciences and Biotechnology, \\ Korea Chiversit; Seoul 136-701, Korea. ${ }^{*}$ E-mail: shpaekiakorea ackr \\ Food Safetv Research Center, National Fisheries Research and Development lnstitute, Busan 619-902, Korea \\ Department of Biotechnology, Korea Lnwersitw, Jochiwon, Choongnam 339-800, Korea \\ Received October 6. 2009. Accepted October 19, 2009
}

\begin{abstract}
An enzyme-linked immunosorbent assay (ELISA)-on-a-chip (EOC) biosensor combined with cell concentration technology based on immuno-magnetic separation (IMS) was investigated for use as a potential tool for early screening of Listeria monocytogenes ( $L$. monocytogenes) in food products. The target analy te is a well-known pathogenic foodbone microorganism and outbreaks of the food poisoning typically occur due to contamination of nomal food products. Thus, the ain of this study was to develop a rapid and reliable sensor that could be utilized on a daily basis to test food products for the presence of this pathogenic nicroorganism. The sensor was optimized to provide a high detection capability (e.g., $5.9 \times 10^{3}$ cells $/ \mathrm{mL}$ ) and, to eventually minimize cultivation time. The cell density was condensed using IMS prior to analysis. Since the concentration rate of IMS was greater than 100 -fold, this combination resulted in a detection limit of 54 cells $/ \mathrm{mL}$. The EOC-IMS coupled analytical sy stem was then applied to a real sample test of tish intestines. The system was able to detect $L$. monocytogenes at a concentration of $2.4 \mathrm{CFU} / \mathrm{g}$ after pre-enrichment for $6 \mathrm{~h}$ from the onset of cell cultivation. This may allow us to monitor the target analyte at a concentration less than 1 CFU/g within a 9 h-cultivation provided a doubling time of 40 min is typically maintained. Based on this estimation, the EOC-IMS system can screen and detect the presence of this microorganism in food products almost within working hours.
\end{abstract}

Key Words: Food-borne microorganism. Early detection. Quantitative analysis. High sensitivițy. Immunomagnetic separation

\section{Introduction}

The genus Listeria is a Gram-positive. non-spore-forming rod-shaped pathogenic bacterium. ${ }^{1}$ A well known bacterial infection, referred to as listeriosis. is ty pically caused by Listeria monocytogenes (L. monocytogenes) and occurs primarily in newborn infants. elderly patients, pregnant women and patients who are immuno-compromised. "The symptoms of listeriosis include vomiting. nausea. stomach cramps, diarrhea, severe headache constipation persistent fever, and convulsions. The microbe can grow over a wide range of temperatures ( 1 to $45^{\circ} \mathrm{C}$ ). which makes it dangerous. particularly, for refrigerated food products that require long-term maintenance. ${ }^{3-5}$ Since the microorganism is widespread in nature. it is present in not only food products. but also in natural environments such as water. air. soil. water plants. and waste water. ${ }^{5}$ Therefore. rapid. accurate, and simple analytical methods are needed to reliably identify $L$. monocytogenes in food products and natural environments encountered by humans.

Three methods are applicable to microorganism detection: colony culture. which is the conventional method, ${ }^{6-8}$ genetic approaches that are based on the polymerase chain reaction. ${ }^{9.11}$ and immunological assay s $s$ iz-15 such as enzy me-linked immunosorbent assay (ELISA). Although the conventional method is the most reliable method for detecting the existence of mic-

\footnotetext{
${ }^{2}$ These authors equally contributed to this research.
}

robes in contaminated food. completion of the analysis is laborious. conplicated. and time-consuning (e.g.. 5 days). ${ }^{16}$ Such drawbacks can be reduced if the genetic or immunological approach is relatively rapid, sensitive and reproducible. and easy-to-use protocols are employed. Nevertheless. the analytical methods still require multiple reaction steps. long reaction time. well-equipped facilities, and skilled technician in addition to the need for a pre-enrichment process through cultivation. ${ }^{1 \text { ? }}$ Therefore. the currently available techniques are inadequate screening methods. particularly, for food products that require a fast distribution time such as frozen foods. marine foods. and vegetables.

For rapid tests. an immuno-chromatographic assay based on lateral flow by means of the capillary phenomenon through membrane strips was developed. ${ }^{18}$ This method has the advantage of reduced analytical time (within $20 \mathrm{~min}$ ), easy-to-handle. and one-step analysis. The device is usually fornulated as a qualitative kit. offering yes-or-no results and uses colloidal gold as the tracer, which is perceivable by the naked eyes. ${ }^{19.21}$ However, this chromatographic assay has not been able to achieve a low detection linit (e.g., $10^{5}$ cells $/ \mathrm{mL}$ ) of the target analyte in samples compared to ELISA. which is the traditional immunoassay .- Due to this inferior performance, this technique may not be able to detect the target microorganism at the concentration levels it exists in certain food products. Moreover, the law demands that food products nust be screened at a level where even a single cell of the food-poisoning bacterium must 
be detected. Thus. it is necessary to develop a rapid analytical system with high sensitivity that can be used for the early detection of a low number of bacterium after pre-enrichment by cultivation.

In this study, we examined the potential of using the ELISAon-a-chip (EOC) biosensor to detect $L$. monocvtogenes based on the concept of cross-flow chromatography. ${ }^{\text {t..4 }}$ This method would simultaneously provide a high analytical performance. high sensitivity and rapidity. all of which are required for early detection. To firther enhance the detection capability. this biosensor technology was combined with immuno-magnetic separation (IMS) ${ }^{2 *}$ to concentrate the cells prior to analy sis using the EOC sensor. This would allow us to measure a minimal number of the food-poisoning agent in a shortened time period after the onset of cell cultivation. Such an analysis scheme would allow one to screen contaminated food within working hours without delaying distribution. In this study we constricted an EOC sensor system and optimized the testing conditions for the detection of the microorganism. In addition. the analytical approach combined with IMS was then assessed by employing a real sample inoculated with trace amounts of $L$. monocitogenes to further test its usability for the early detection of contamination.

\section{Methods}

Construction of EOC Sensor System. Labeling of Antibody with Horseradish Peroxidase: Mouse monoclonal antibody LZF7 (HyTest. Turku. Finland) which recognizes the outer membrane fraction and intact cells of L. monocytogenes was chemically conjugated to horseradish peroxidase (HRP: EDM chemicals, Gibbstown. NJ). via a cross-linker following a protocol described elsewhere. ${ }^{-2}$ Briefly, the antibody $(2.65 \mathrm{nM})$ was first reduced using $10 \mathrm{mM}$ dithiotheritol (Pierce. Rockford. II). at $37^{\circ} \mathrm{C}$ for $1 \mathrm{~h}$ and the excess reagent was removed on a Sephadex G-15 gel column ( $10 \mathrm{~mL}$ volume). HRP (26.45 nM) was activated with a 25 -fold molar excess of $661.29 \mathrm{nM}$ succinimidỵl 4-[1-maleimidomethỵl]cyclohexane-1-carboxylate (Pie-

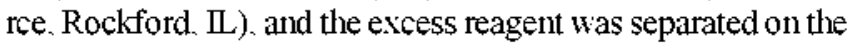
same gel column. The activated antibody was then combined with 5-fold molar excess of the activated HRP and the conjugation was carried out at $4{ }^{\circ} \mathrm{C}$ overnight. The synthesized conjugates were stored as aliquots after snap freezing.

Preparation of Immuno-strip: An immuno-strip, which was installed within the EOC, was prepared as described elsewhere ${ }^{2}$ The strip consisted of four different types of functional membrane pads consecutively connected by partial superimposition. They were. from the bottom. the glass fiber membrane (4 mun $\times 15 \mathrm{~mm}$, Allstrom 8980; Whatman, Kent, UK) for sample application, glass membrane $(+\mathrm{mm} \times 5 \mathrm{~mm}$. PT-R5: Advanced Microdevices. Ambala Cantt. India) for the release of the detection antibody labeled with HRP, nitrocellulose membrane ( $4 \mathrm{~mm} \times 25 \mathrm{~mm}$. 70CNPH-N-SS40: Advanced Microdevices. Ambala Cantt. India) for signal generation, and cellulose membrane ( $4 \mathrm{~mm} \times 15 \mathrm{~mm} .17 \mathrm{CHR}$ : Whatman. Kent. UK) for absorption. The signal generation pad was prepared by dispensing ( $1.5 \mu \mathrm{L} / \mathrm{cm}$ ) the monoclonal antibody ( $1 \mathrm{mg} / \mathrm{mL}, \mathrm{LZHl}$; HyTest, Turku. Finland) for the analytte line and goat anti-mouse IgG
$(0.1 \mathrm{mg} / \mathrm{nL}$ ) for the control on the pre-determined sites, 5.5 and $11.5 \mathrm{~mm}$ from the bottom respectively, using a micro-dispenser (BioJet3000. BioDot. Irvine. CA)

Fabrication of EOC: The EOC. which was comprised of top and bottom plastic plates made by injecting polycarbonate molding. was fabricated as previously reported. ${ }^{26}$ After placing the immuno-strip and a horizontal flow absorption pad (cellulose membrane; $1+\mathrm{mm} \times 12 \mathrm{num}$ ) within the vertical channel and the absorption pad compartment of the botton plate, respectively. the two plates were firmly combined using groove joints to produce the EOC. The assembled EOC was stored in a desiccator maintained at room temperature prior to use.

Analytical Perfomance of the EOC Biosensor. Analytical Pocedure: The procedure used to detect and analyze the presence of $L$. monocytogenes was previously described. ${ }^{2.2+}$ Briefly, standard samples of $L$. monocytogenes cells $(100 \mu \mathrm{L})$ in 10 mM phosphate buffer containing $140 \mathrm{mM} \mathrm{NaCl}$. pH 7.4. (PBS) was applied to the sensor and the vertical flow was maintained for 15 min to complete the immune reactions. The horizontal flow absorption pad was then connected to the lateral side of the signal generation pad and $150 \mu \mathrm{L} 3.3^{\prime}, 5.5^{\prime}$-tetranethylbenzidine for membranes (TMB-M: Moss. Pasadena. ML) was supplied into the substrate supply pot. After the enzyme reaction was allowed to proceed for $5 \mathrm{~min}$. the detectable color signal produced on the signal generation pad was captured as inages using a digital camera. installed within the colorimetric detector. The color signals on the captured image were quantified along the center line of the inumuno-strip in the vertical direction using software as described elsewhere. The analysis was repeated three times for the same sample and. to establish the calibration curve. the mean values for each sample were plotted against the analy te concentration

Cross-reactivity Test: The specificity of the EOC biosensor was tested by carning out cross-reactions with the following bacterial species: Salmonella tuphimurim (S. Tphimurim), Salmonella cholerasuis (S. cholerasuis). Salmonella bongori (S. bongori), Salmonella enteriaca subsp. arizonae (S. enteria subsp. arizonae). Salmonella enterica subsp. houtenae (S. enterica subsp. houtenae). Salmonella enteritidis (S. enteritidis). Shigella flexneri (St flemeri), ribrio parahaemolvticus ( $\mathrm{I}$. parahaemolvicus), Iibrio hitoralis ( $r$ : hitoralis), Listeriagravi ( $L$. gravi), Listeria imnocua (L. imnocua). Listeria welshmeri ( $L$. welshmeri). Escherichia coli ( $E$. coli). Bacillts cereus (B. cereus). Streptococcus mutans (S. mutans), Lactobacilhis plamarum (L. plantarum). Psuedomonas fluorescens (P. fluorescens), Clostridium perfringens ( $C$. perfringens). and Staphylococcus aureus (S. aureus). L. monocytogenes (ATCC 19117) was obtained from the American Type Culture Collection (ATCC: Manassas. VA). Other standard bacterium species were supplied by the Korean Collection for Type Cultures (Biological Resource Center. Daejon Korea). The EOC analy ses were performed as described. where each sample contained $10^{8}$ cells $/ \mathrm{nL}$ microorganism in PBS.

Cell Concentration by IMS. Antibody Coating on Magnetic Beads: The monoclonal antibody (LZF7: total $120 \mu \mathrm{g}$ ) was conjugated to magnetic beads (total $4 \times 10^{8}$ particles: Dynabeads M-270 Amine. Invitrogen, Carlsbad, CA) containing anine functional groups on the surfaces. according to the protocol 
provided by the manufacturer. Briefly, the beads $(200 \mu \mathrm{L}$ of $30 \mathrm{mg} / \mathrm{mL}$ ) were sufficiently washed with $100 \mathrm{mM} 2-(\mathrm{N}$-motpholino)ethanesulfonic acid (Pierce, Rockford. IL). pH 4.5 . and then chemically coupled with the antibody ( 100 !L of 1.2 $\mathrm{mg} / \mathrm{mL})$ after addition of a mixture $(120 \mu \mathrm{L})$ of $0.13 \mathrm{mM} N$ hydroxysulfosuceinimide (lieree. Rockford, IL) and $0.05 \mathrm{mM}$ l-ethyl-3-(3-dimethylaminopropyl) carbodiimide (Pierce, Rockford. IL) in deionized water. lhe reaction was carricd out at room temperature for $2 \mathrm{~h}$. To block the residual active sites on the beads. I Methanolamine. pI I 8.5. ( $12.2 \mu \mathrm{L}$.) was added and incubated at room temperature for $15 \mathrm{~min}$. The bead surfaces were linally blocked in PBS containing $0.5 \%$ casein $(0.5 \%$ Cascin-PBS). After the solution was magnetically separated, the inmuno-beads were re-suspended in I mL of PBS (the final concentration $6 \mathrm{mg}$ beads per $\mathrm{mL}$ and approximately $20 \mu \mathrm{g}$ antiloody per $1 \mathrm{mg}$ bead) and stored at $4{ }^{\circ} \mathrm{C}$ until used.

IMS Procedure: The L. monocytogenes sample ( $10 \mathrm{~mL}$ ) was concentrated by adding the immuno-beads $(150 \mu \mathrm{L}$ ). reacting for I h on a shaket at room temperature, and magnetically separating the supematant. To recover the cell concentrate from the magnetic beads, $10 \mathrm{mM}$ glycine, pH $1.5,(60 \mu \mathrm{L})$ was added, incubated for $30 \mathrm{~min}$, and magnetically separated again. The collectcd cell suspension was neutralized with $\mathrm{I} \mathrm{M}$ Iris-HCl. $\mathrm{pH} 8.5$, (30 $\mu \mathrm{L}$ ) and sequentially stabilized by adding $5 \%$ CaseinPBS $(10 \mu \mathrm{L})$. I The concentrated cells (total $100 \mu \mathrm{L})$ were then subject to analysis using $\mathrm{EOC}$.

Real Sample Test. Sample Preparation: Flatfïsh was kindly provided by the National risheries Rescarch and Development Institute (NFRDI, Busan, korea) and used to assess the ability of the FOC biosensor system combined with IMS to detect $l$. monocytogenes in a real sample. To this end, the fish intestines were collected and employed as real sample matrices. According to the standard protocol for sample preparation. "ine intestines ( $10 \mathrm{~g}$ ) were grinded in $90 \mathrm{~mL}$ Listeria enrichment broth (1.ГВ; Merck, Darmstadt. Germany) containing $0.5 \%$ ycast extracts.

Test Procedure. The prepared samples were artificially inoculated with a 24 colony-forming unit (CFU) of $L$. monocytogenes and then cultivated under continuous shaking at $37^{\circ} \mathrm{C}$ for different time periods in the range of $3 \mathrm{to} / 2 \mathrm{~h}$. At pre-determined limes, each sample was concentrated via IMS and analyzed using the $\mathrm{EOC}$ biosensor system. The same experiment for each sample was repeated three times.

\section{Resulks and Discussion}

Analytical Perfomances of the FOC Biosensor. Analytical Procedure: Using the $\mathrm{EOC}^{2}$, the microorganism can be analyzed and detected in a seguential two-step manner: antigen-antibody binding and enzyme reaction. The sample absorbs to the botton of the immuno-strip after it is added to the system and the analyte first reacts with the detection antibody labeled with the enzyme, IIRP, pre-loaded on the conjugate release pad. The aqueous mixture is then transferred by capillary action to the capture antibody. LZI II, which also recognizes the L. monocytogenes cells as a binder of the sandwich pair with 1.7.F.7. immobilized on a pre-determined site of the signal generation pad of the strip where the sandwich-type immune complex forms (vertical flow). To generate signals from the enzyme, the enzyme substrate is supplied into the pot after placing the horizontal absorption pad on the lateral side of the signal pad. Ihe substrate then flows in the horizontal direction such that the excess reagents are washed away from the strip and the enzyme reaction is initiated at the same time (horizontal flow). The color signals are produced on the site of antibody immobilization in proportion to the analyte concentration. On the top position of the capture site. a secondary antibody (goat anti-mouse $\lg G$ ) is bound to produce the control signal that is constant regardless of the analyte concentration. The color signals were quantified by employing a colorimetric detector equipped with a digital camera and software installed in the personal computer to digitize the color inage.

Dose Responses. By following the pre-determined procedure, immuno-chromatographic assays were conducted to obtain the sensor responses to concentration changes of L. monocytogenes. The color signals (at the position indicated as Analyte)
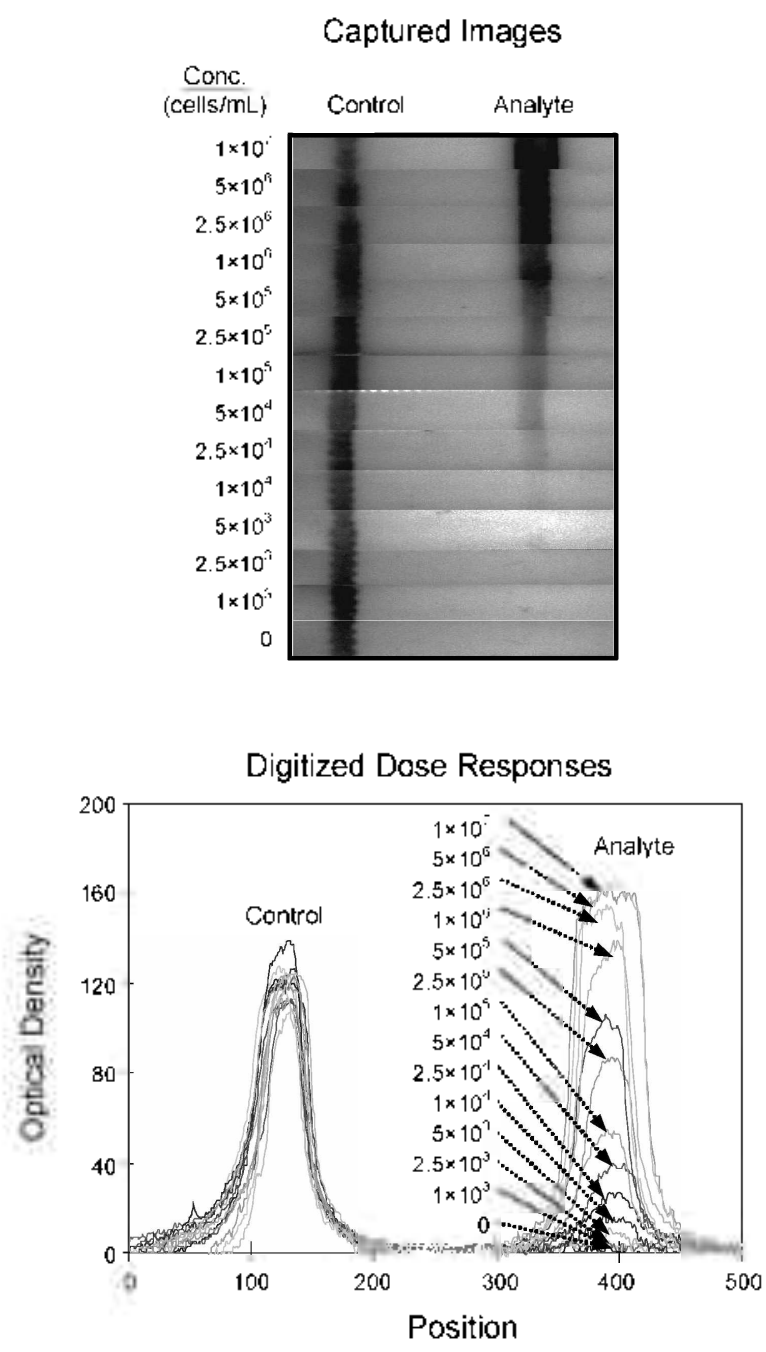

Figure 1. Dose responses of the EOC biosensor system to the concentration of $L$. monocylogenes. After analyses, the produced color signals were captured as images, showing a direct proportionality to the analyte dose ( upper part). The signals were then digitized to optical densitics using soltware and plotted against the position on the signal generation pad (lower part) 


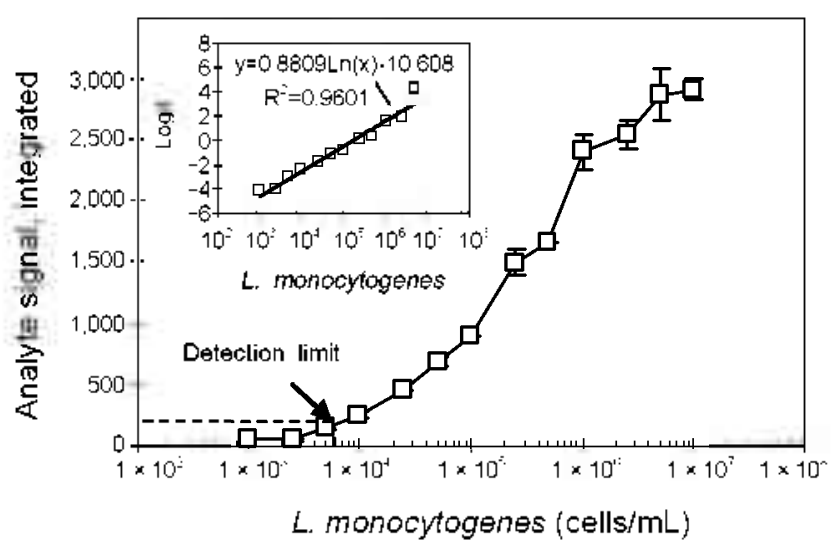

Figure 2. Calibration curve of the EOC biosensor for $L$. monocvtogenes. The digitized color densities for each analyte dose (reter to Fig. 1 , lower part) were integrated and then plotted against the concentration. The sigmond-type curve was converted to a lineanzed graph via logit- log transfonnation (the inset). Variation in three repetitive measurements at each determmation was indicated. See text for a more detaled explanation.

Immuno-magnetic Separation (IMS)

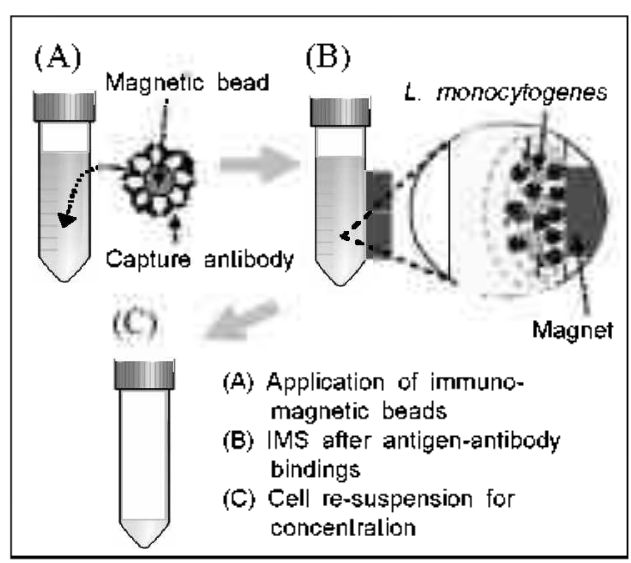

Determination of Concentration Rate

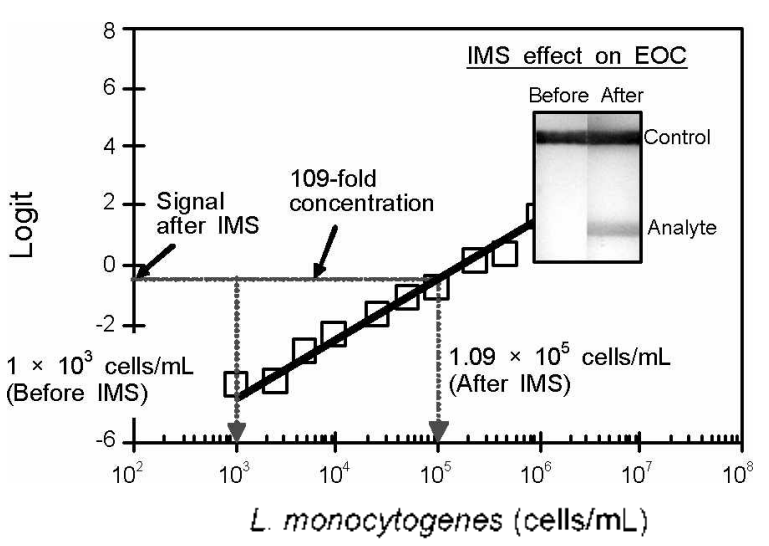

Figure 3. Schematic representation of the immuno-magnetic separation (IMS) process ( upper part) and detemunation of the cell concentration rate usung the EOC-based analy tical method (lower part). The L. monoortogenes sample at a dose $\left(\mathrm{e} . \mathrm{g}, \mathrm{l} \times 10^{3}\right.$ cells $/ \mathrm{mL}$ ) below the detection limit was enriched by IMS and then analyzed on the EOC (reter to the results before and after IMS in the inset). The measured signal was used to deternine the correspondung concentration of the cells on the lunearized calibration curve.

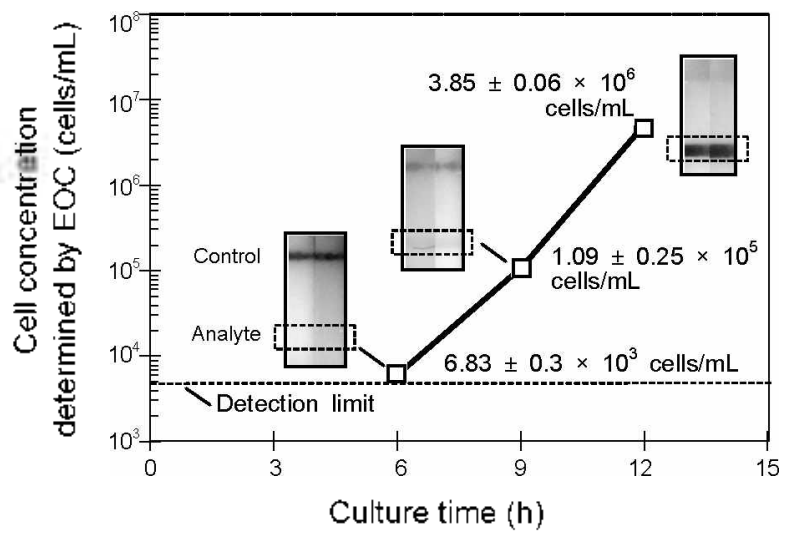

Figure 4. Real sample tests by means of the IMS-coupled EOC sensing at different cultivation time after the inoculation of L. monocvtogenes cells into fish intestines. The inoculum density was $0.24 \mathrm{cells} / \mathrm{mL}$ and the sample was cultured in LEB medium. At each pre-detenmmed time, the medium was analyzed and the concentration was determined using the calibration curve obtained for the EOC biosensor shown in Figure 2. Standard variations of three measurements for each determination were indicated.

that appeared on each EOC were proportional to the analyte dose (Figure 1. upper part) in the range of approximately $5 \times$ $10^{3}$ to $1 \times 10^{6}$ cells $/ \mathrm{mL}$ if detennined by the naked eyes. The signals were then converted to optical densities via digitization of the image using the software developed in this laboratory. The density values were normalized by subtracting them from the mean value between the Control and Analyte bands (i.e., the background color density') and then plotted against the position on the signal generation pad (Figure 1, lower part). The signal curve dimension increased as the dose was elevated in the standard samples (Analyte) while the signal from the control remained relatively constant ( $\mathrm{Control}$ ). This plot showed that the curve measured at a cell concentration of $2.5 \times 10^{3} \mathrm{cells} / \mathrm{mL}$ was barely distinguishable from that at the zero dose.

To prepare the calibration curve for L. monocntogenes, the normalized optical densities for each peak were integrated to detenmine the signal values corresponding to the respective analyte concentration. The integrated signal was then plotted against the analyte concentration (Figure 2), which had a sigmoidal pattern identical to those previously reported ${ }^{2+. .66}$ From this curve, we were able to deternine the analytical sensitivity of the EOC biosensor. which was the concentration that matched the signal value obtained by multiplying the standard deviation of the integrated signal at the zero dose by three. ${ }^{2,23}$ The resulting detection capability of the EOC biosensor was determined to be $5.9 \times 10^{3}$ cells/mL and the quantification limit was determined to be $1.06 \times 10^{4}$ cells/mL by multiplying this value by a factor of five. ${ }^{26}$ The calibration curve was linearized (correlation coefficient: $\mathrm{R}^{2}=0.9601$ ) via logit-log transfonnation (the inset of Figure 2$)^{3-2}$ so that it could be used to accurately deternine the analyte concentrations in unknown samples.

Coss-reactivity: In addition to the detection capability. it was also inportant to examine the specificity of the biosensor system to the target microorganism. The two monoclonal antibodies used as the capture and detection binders were claimed to show selective reactivities to $L$. monocyogenes by the manu- 
Table 1. Cross-reactivities of the EOC biosensor system for L. monocytogenes.

\begin{tabular}{|c|c|c|}
\hline & Strain & $\begin{array}{l}\text { Analytical results } \\
\text { at } 10^{8} \text { cells } / 11 \mathrm{~L}\end{array}$ \\
\hline 1 & S. typhimmitm (ATCC 13311) & $-{ }^{a}$ \\
\hline 2 & S. cholemestis (ATCC 10708) & - \\
\hline 3 & S. bongori (ATCC 43975) & - \\
\hline 4 & S. bongori (ATCC 12397) & - \\
\hline 5 & S. enterica subsp arizonae (ATCC 12323) & - \\
\hline 6 & S. entertica subsp hontenae (ATCC 43974) & - \\
\hline 7 & S. enteritidis (ATCC 13076) & - \\
\hline 8 & S.flexteri (ATCC 29903) & - \\
\hline 9 & I. Parahaemotyficus (ATCC 27519) & - \\
\hline 10 & I. Parahaemolvticus (ATCC 17802) & - \\
\hline 11 & F. litoralis (ATCC 12520) & - \\
\hline 12 & I. parahaemolyticus (ATCC 27969) & - \\
\hline 13 & L. monocytogenes (ATCC 19117) & $+b$ \\
\hline 14 & L. gravi (ATCC 19120) & + \\
\hline 15 & L. inhocua (ATCC 33090) & + \\
\hline 16 & L. welshmeri (ATCC 35897) & + \\
\hline 17 & E. coli (ATCC 43888) & - \\
\hline 18 & B. cerius (ATCC 21366) & - \\
\hline 19 & S. mitums (ATCC 27607) & - \\
\hline 20 & L. plantanm (ATCC 14917) & - \\
\hline 21 & P. fluorescens (ATCC 49642) & - \\
\hline 22 & C.perfingens (ATCC 3624) & - \\
\hline 23 & S. awretis (ATCC 25923) & - \\
\hline
\end{tabular}

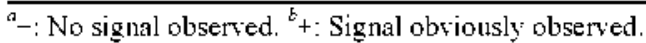

facturer. The antigenic sites of the bacterial cell. however. might be analogous to those on other species such as lipopoly saccharides (LPS) and three types of surface antigens (K- O-. and $\mathrm{H}$-antigens). ${ }^{2 /}$ The microorganisms used to test the cross-reactivity of the sensor were the Salmonella species. Tibrio species. Listeria species. and other pathogenic species (Table 1). The analyses were carried out for the samples containing a high concentration (e.g.. $10^{8}$ cells $/ \mathrm{mL}$ ) of each species and showed that the EOC biosensor did not cross-react with other bacteria except the Listeria species. Nevertheless. since the sensor was not able to discriminate the pathogenic species. L. monocytogenes. from the others of the same genus. the specificity was needed to be further improved. This can be achieved in a future study, by producing and screening appropriate monoclonal antibodies that react solely with the target microorganism.

Enhancement of Detection Capability. Since L. monocrtogenes can rapidly grow when incubated under optimal conditions. the presence of even extremely low concentrations of $L$. monoctrogenes (e.g.. a single cell per $10 \mathrm{~g}$ specimen) in food products is not legally allowed. However. such low titers cannot be directly detected using most analytical means. Thus. the analyte is usually enriched by cell cultivation until the titer reaches detectable levels. ${ }^{18}$ To decrease the cultivation period. which is the time-limiting process. we devised an analy tical scheme to concentrate the cells immediately prior to detection.

IMS-coupled Analysis: IMS can be used to rapidly concentrate $L$. monocytogenes cells and may be carried out in the field where the food specimens are funished. To exanuine the ability of this method to concentrate $L$. monocvtogenes. we first chemically linked the capture antibody. specific to the microorganism. on the surfaces of magnetic beads and then added the conjugates into an aqueous solution containing the cells (Figure 3. upper part: A). After the antigen-antibody reaction, the complexes were isolated via IMS (B), the solution was removed. and the products were re-suspended in a ninimal volume of acidic solution $(\mathrm{C})$. The cells that dissociated from the beads under the acidic condition were retrieved using IMS again and then, after neutralization of the $\mathrm{pH}$. the samples were subject to EOC analysis.

A sample containing $1 \times 10^{3}$ cells $/ \mathrm{mL}$ of $L$. monocytogenes, which was initially not detectable by the sensor, was concentrated wia IMS and then analyzed by EOC. The color signal was quantified as previously described and used to deternine the concentration after IMS through the linearized calibration curve (Figure 3, lower part). The cell density was increased up to $1.09 \times 10^{5}$ cells $/ \mathrm{mL}$. indicating that concentration rate by IMS was 109 -fold. Consequently. the detection capability of the IMS-coupled EOC analy sis was as low as 54 cell $\mathrm{s} / \mathrm{mL}$ of L. monocytogenes in the original sample. The cell concentration effect even produced on-off color signals after and before IMS, respectively (see the inset).

Tests with Real Sample. As mentioned above, L. monocvtogenes may be present in contaminated food products in trace quantities that cannot be directly detected by means of the IMScoupled EOC biosensor technology. Thus, cell cultivation for pre-enrichment is generally required before sample analysis. ${ }^{13}$ which is a time-consuming step. Several studies have attempted to shorten the cultivation time ${ }^{18.28}$ with the goal of developing an early screening method against food contanination that is reliable and rapid.

Enrichment by Cultivation: We employed a real sample. e.g. fish intestines. to determine the pre-enriclunent time of the bacterium. inoculated into the sample. needed to reach a cell concentration that is detectable by the sensor. The sample may contain a diverse range of different microorganisms that might interfere with the sensors ability to specifically detect the target analyte. The L. monocvtogenes cells ( $2.4 \mathrm{CFU} / \mathrm{g}$ ) were artificially inoculated into the real sample and were cultured (inoculation density: $0.2+\mathrm{CFU} / \mathrm{mL}$ ) for different time intervals. To determine a minimum cultivation period. the cell culture was analyzed at pre-deternnined times using the IMS-coupled EOC sensing protocol as described above.

Based on the analytical results (Figure 4). the microorganism inoculated into the sample was detected by the EOC biosensor after concentration by IMS after $6 \mathrm{~h}$ from the onset of cultivation. The cell concentration determined from the standard curve was $6.83 \pm 0.3 \times 10^{2}$ cells $/ \mathrm{mL}$ after IMS. which was somewhat above the detection limit of the EOC biosensor $\left(5.9 \times 10^{3}\right.$ cells/ $\mathrm{mL}$ ). If the condensation factor by IMS (typically. 109-fold) was considered. the cell density in the culture was expanded to $62.7 \mathrm{cells} / \mathrm{mL}$. Thereafter, the growth curve showed a nearly straight line in the semi-log plot during the monitoring time period. indicating that the culture was maintained in the log phase of the growth. When the bacteria cells began to divide into two daughter cells (i.e.. binary fission), the cell number was 
augmented in the form of logaritlumic pattern. ${ }^{23}$

Since the inoculated cells $(0.24$ cells $/ \mathrm{mL})$ expanded to 62.7 cells $/ \mathrm{mL}$ in the initial $6 \mathrm{~h}$ of cultivation the doubling frequency of the culture was estimated to be 8 times on the basis of 40 min per one binary fission in the LEB medium. ${ }^{29.31}$ This estimation also suggested a lag phase period of about $40 \mathrm{~min}$, during which the individual cells matured but were not yet able to divide. ${ }^{-9}$ Due to cell growth the cell concentration should increase up to $1.00 \times 10^{3} \mathrm{cells} / \mathrm{mL}$, if there was an average of 4 doublings over the next $3 \mathrm{~h}$ (for total $9 \mathrm{~h}$-culture). and up to $3.21 \times 10^{4}$ cells $/ \mathrm{mL}$ with 7 doublings over the next $6 \mathrm{~h}$ (for total $12 \mathrm{~h}$ ). These estimations were very close to the experimental values. $1 \times 10^{3}$ and $3.53 \times 10^{4}$ cells $/ \mathrm{mL}$ after a 9 and $12 \mathrm{~h}$ cultivation period. respectively, which was calculated by dividing the measured densities using the EOC by the IMS condensation factor of 109

It is worth noting that. in regards to the lag phase. the time period was not extended for very long even though an extremely low bacterial concentration was inoculated. According to previous reports. ${ }^{31.32}$ a long lag phase was often encountered with cells that were subjected to stress by physical damage. heat treatment or starvation. Since the cells grown in the middle of the exponential phase were used for the inoculation in this study, they may spend only a short time in the lag phase to allow them to adopt to the new environment and subsequently grow in a logarithmic pattern.

\section{Conclusions}

The EOC sensor combined with IMS was able to detect 0.24 cells $/ \mathrm{mL}$ of L. monocytogenes inoculum in culture $(2 .+\mathrm{CFU} / \mathrm{g}$ intestines as sample) after $6 \mathrm{~h}$ from the onset of pre-enrichment. It was inferred based on a 40 -min doubling time of $L$. monocyogenes that the same sample containing $1 \mathrm{CFU} / \mathrm{g}$ could be detected within approximately $9 \mathrm{~h}$ when this novel analytical method was used. Although the lag phase in the culture may increase with a decrease in the inoculum size. IMS would compensate for the loss in total analy'sis time due to its ability to concentrate the sample by 109 -fold. The EOC sensor performance was superior to those of other commercial rapid test kits currently available in regards to shortening the total assay time for detection of the microorganism to within working hours. It would be expected that the biosensor system can be utilized in places where an early food screening against microbial contamination is required. We are currently devising a system that physically combines both IMS and detection using the EOC biosensor, which would allow one to sequentially conduct the both processes.

Acknowledgments. This research was support by a grant (Grant mumber: 20050078) from the specific marine technology development program funded by the Ministry of Land. Transport and Maritime Affairs of the Korean government

\section{References}

1. Ramaswanny, V.; Cresence, V. M.: Rejitha, T. S.; Lekshnni, M. U.:
Dharsana, K. S.; Prasad, S. P.: Vijila, H. M. J. Aficrobiol Immmol. Infect. 2007, 40,4 .

2. Shyamal, K. M.; Ronald N.; Frederick, C. P. Appl Enwinon. Aicrobiol. 1986, 52, 510 .

3. Dykes, G. A.; Dworaczek, M Lett. Appl A ficrobiol 2002, 35, 538.

4. Heisich, T. E.; Wagner, D. E.; Nieman, M. L.; Peeler, J. T. Appl. Environ. Afichobiol. $1989,55,1925$.

5. Fleming, D. W; Cochi, S. L.; Macdonald, K. L.; Brondum, T; Hayes, P. S.; Plikaytis, B. D.; Holmes, M. B.: Audurier, A.: Broome, C. V.; Reingold, A. L. N. Engl. J. Med. 1985, $312,404$.

6. Scotter, S. L.; Langton, S.; Lombard, B.; Schulten, S.; Nagelkerke, N.; Veld P. H.; Rollier, P.; Lahellec, C. Int. I. Food Microbiol. $2001,64,295$

7. Takkai, S.: Orii, F.: Yasuda, K.: Innone, S.: Tsubaki, S. hicrobiol. Inmmol. 1990, 34,631.

8. Reissbrodt, R. Int. J. Food M/icrobiol 2004, 95, 1

9. Navas, T; Ontiz, S.; Lopez, P.; Tantzen, M M.; Lopez, V:; Martinez, J. V. Foodborne Pathog. Dis. 2006, 3, 347.

10. Nilsson, H. O.; Aleljung. P.: Nilsson, I.; Tyszkiewicz, T.; Wadstrom, T. J. Microbiol Methods 1996, 27,73

11. Ueda, S.; Maruyama, T.; Kuwabara, Y. Biocontrol Sci. 2006, 11, 129

12. Roth, J. J. Histochent Cytochen. 1982, 30,691

13. Skjerve, E; Rovik, L. M.; Olsvik, O. Appl. Environ. Microbiol. $1990,56,3478$

14. Usleber, E.: Abramson, D.: Gessler, R.; Smith, D. M.: Cleat, R. M.; Martlbauer, E. Appl. Emiron. Aficrobiol 1996, 2, 3858.

15. Xiulan, S.; Xiaolian, Z.; Jian, T; Zhou, J.; Chu, F. S. Int. J. Food Microbiol. $2005,99,185$.

16. Hao, D. Y.: Bcalchat, L. R.; Brackett, R. E. Appl Emiron M/iciobiol $1987,53,955$

17. Hearty, S.; Leonard, P.; Kennedy, R. J. Mficrobiol. M lethods 2006. 66,294

18. Shim, W. B.; Choi, J. G.; Kim, J. Y.; Yang, Z. Y.; Lee, K. H.; Kim, M. G.; Ha, S. D.: Kim, K. S.; Kim, K. Y.; Kim, C. H.; Ha, K. S.; Eremin, S. A.: Chung, D. H. J. Microbiol Biotechol 2007, 17, 1152

19. Bautista, D. A.; Elankumaran, S.; Arking, T. A.; Heckert, R. A. J. ret. Diagn. Invest. $2002,14,427$.

20. Faulk, W. P.; Taylor, G. M. Immtnocytochem. 1971, 8, 1081.

21. Moeremans, M:; Daneels, G.: Dijek, A. V.; Langanger, G.: Mey, J. D. J. Immmol . Methods $1984,74,353$

22. Cho, J. H.; Han, S. M.; Paek, E. H.; Cho, I. H.; Paek, S. H. Anal. Chem. 2006, 78, 793 .

23. Paek, S. H.; Cho, J. H.; Cho, I. H.; Kim, Y. K.; Oh, B. K. Bio. Chip. J. 2007, 1, 1

24. Han, S. M:; Cho, I. H.: Cho, I. H.: Patek, E. H.; Oh, H. B.; Kim. B. S.: Ryu, C. S.: Lee, K. H.; Kim, Y. K.; Paek, S. H. Anal Chm. Acta 2007, 587, 1

25. Entoth, H.; Engstrand, L. J. Clin. Hicrobiol. 1995, 33, 2162.

26. Cho, I. H.; Paek, E. H.; Kim, Y. K.; Kim, J. H.: Paek, S. H. Anal. Chim. Acta 2009, 632, 247 .

27. Heather. S.: Helene, M. Infection. Immunits. 2006. 74, 6675

28. Shim, W. B.; Choi, J. G.; Kim, J. Y.; Yang, Z. Y.; Lee, K. H.; Kim, M. G.; Ha, S. D.; Kim, K. S.; Kim, K. Y.; Kim, C. H.; Ha, K. S.; Eremin, S. A.; Chung. D. H. J. Food Prot. 2008, 71, 781

29. World Health Organization: Food and Agriculture Organization of the United Nations. Risk assessment of Listeria monocytogenes in ready-to-eat foods: Techuical report: Geneva, Switzerland, $2004 ;$ p. 80

30. Cheryl, L. B; Veronica, C.; Natalia, A. K ; Benjamin, E. S.; Darren, E. H.: Joln, H. B. Name 2008, $451,350$.

31. Augustin, J. C.: Agnes, B. D.: Laurent, R.: Vincent, C. Appl. Environ. Aficrobiol 2000, 66, 1706.

32. Besse, N. G.; Audient, N.; Barre, L.; Cauquil, A.; Conn, M.; Colin, P. Int. J. Food Hicrobiol. 2006, 110,43. 